\title{
MAPEAMENTO DE COMPETÊNCIAS DE EQUIPES DESENVOLVEDORAS: UM OLHAR NA CONSTRUÇÃO INTERDISCIPLINAR DE MATERIAIS EDUCACIONAIS DIGITAIS
}

\author{
MAPEAMENTO COMPETENCY MAPPING OF DEVELOPMENT TEAMS: \\ A LOOK UPON THE INTERDISCIPLINARY MAKING OF \\ DIGITAL LEARNING RESOURCES
}

\section{IDENTIFICACIÓN DE COMPETENCIAS DE LOS EQUIPOS DESARROLLADORES: UN ENFOQUE EN LA CONSTRUCCIÓN INTERDISCIPLINAR DE MATERIALES EDUCATIVOS DIGITALES}

\section{Cristina Alba Wildt Torrezzan ${ }^{1}$ Patricia Alejandra Behar ${ }^{2}$}

\begin{abstract}
RESUMO: Este artigo apresenta um mapeamento das competências necessárias às equipes desenvolvedoras de materiais educacionais digitais, desenvolvido com base em referencial teórico e um estudo de caso. O principal objetivo é apoiar a interlocução entre as distintas funções de cada membro de equipes interdisciplinares durante a elaboração desses materiais. O trabalho descreve o processo de validação de competências, que ocorreu por meio da aplicação de questionários e do cruzamento de dois mapeamentos: o primeiro foi realizado com base em levantamento bibliográfico e o segundo, elaborado em curso de extensão. O intuito é auxiliar professores, designers e programadores na gestão das atividades responsáveis pela construção de materiais educacionais digitais. Os resultados apontam a identificação e a setorização, por equipe, dos elementos envolvidos nessa prática, apoiando a adoção de um percurso metodológico focado, interativo e colaborativo.
\end{abstract}

PALAVRAS-CHAVE: Material didático. Educação. Educação a distância. Abordagem Interdisciplinar.

ABSTRACT: This article presents a pertinent competency mapping to digital learning resources development teams, based on theoretical references and a case study. Its main purpose is to support the interlocution of the different roles of each interdisciplinary team member during the making of such resources. It describes the process of competency validation, which resulted from questionnaire application and the crossing of two mappings. The first mapping was accomplished based on bibliographic research, whereas the second one was performed during an extension course. It aims at providing support to teachers, designers and programmers regarding the organization of digital learning resources development activities. The results highlight the identification and sectorization, by teams, of the elements involved in this practice, supporting the adoption of a focused, interactive and collaborative methodological path.

KEYWORDS: Teaching materials. Education. Distance education. Interdisciplinary approach

RESUMEN: En este artículo se presenta una identificación de las competencias necesarias para desarrolladores equipos de materiales educativos digitales, desarrollado en base a marco teórico y un estudio de caso. El

\footnotetext{
${ }^{1}$ Doutora em Informática na Educação pela Universidade Federal do Rio Grande do Sul - UFRGS, Porto Alegre, RS - Brasil. Pesquisadora voluntária do Núcleo de Tecnologia Digital Aplicada à Educação NUTED/UFRGS, Porto Alegre, RS - Brasil. E-mail: crisawt@gmail.com.

${ }^{2}$ Doutora em Educação pela Universidade Federal do Rio Grande do Sul - UFRGS, Porto Alegre, RS - Brasil. Professora do Departamento de Estudos Especializados da Faculdade de Educação/Universidade Federal do Rio Grande do Sul - UFRGS, Porto Alegre, RS - Brasil. E-mail: pbehar@terra.com.br.
}

Recebido em: 05/07/2015. Aprovado em: 21/02/2016. 
principal objetivo es apoyar el diálogo entre las diferentes funciones de cada miembro de los equipos interdisciplinarios en la preparación de estos materiales. El trabajo describe el proceso de validación de competencias, que se llevó a cabo mediante el uso de cuestionarios y la integración entre dos identificaciones: la primera se basa en la literatura y la segunda, redactado en un curso de extensión. El objetivo es ayudar a los profesores, diseñadores y programadores en la gestión de las actividades responsables de la construcción de materiales educativos digitales. Los resultados muestran la identificación y la compartimentación, por el personal de los componentes involucrados en esta práctica, el apoyo a la adopción de un enfoque metodológico centrado, interactivo y colaborativo.

PALABRAS CLAVE: Material didáctico. Educación. Educación a distancia . Enfoque interdisciplinario.

\section{INTRODUÇÃO}

Por meio da utilização das tecnologias digitais, os materiais educacionais digitais (MEDs) possibilitam interações e interatividades que extrapolam o limite físico da sala de aula. Dessa forma, aproximam a educação do caráter atemporal que vem se instalando na sociedade desde a popularização da internet. $O$ termo material educacional digital é conceituado neste artigo como sendo todo o material voltado à aprendizagem e que utiliza um ou mais recursos digitais na sua elaboração. A referida expressão é utilizada quando não há a necessidade de especificar a natureza do material e ao mesmo tempo abrangendo todas elas. São exemplos de MEDs as páginas web, blogs, $x \boldsymbol{s}$, softwares educacionais e os objetos de aprendizagem (OA), entre outros.

Inicialmente, os MEDs eram elaborados, na maioria das vezes, a partir da simples digitalização de materiais educacionais analógicos. Atualmente, já existe uma maior preocupação em abordar novas práticas educacionais que se relacionem de maneira harmônica aos recursos digitais e, em especial, que sejam centradas na aprendizagem do aluno. Por outro lado, é difícil encontrar uma metodologia de construção de MEDs que, ao mesmo tempo, envolva orientações técnicas (programação), gráficas (design de interface) e pedagógicas (planejamento do conteúdo). Esse fato, por vezes, torna necessária a integração de distintas metodologias e tutoriais que tratem individualmente dessas questões, fornecendo complexidade à prática da equipe desenvolvedora. Um dos maiores desafios está na articulação entre as diferentes funções dos seus membros: professor (conteudista), designer e programador.

Frente a este contexto, verifica-se que essas questões podem ser amenizadas, ou até solucionadas, graças à identificação e setorização das atividades relacionadas a cada agente de equipes interdisciplinares. O mapeamento que será apresentado ao longo deste estudo permite explicitar a responsabilidade de cada profissional para que, a partir dessa consciência, possam construir um percurso metodológico focado, interativo e colaborativo.

Nesse sentido, o presente artigo relata o processo de elaboração e validação de um mapeamento das competências necessárias a equipes desenvolvedoras de materiais educacionais digitais. O objetivo é divulgar os elementos identificados para que possam apoiar a gestão do grupo de trabalho e sugerir um novo olhar a respeito do processo de construção de MEDs: baseado nas competências da equipe interdisciplinar. Dessa forma, nos 
capítulos e seções que se seguem, será primeiramente apresentado o conceito do termo competências e a sua relação com a construção de materiais educacionais digitais. Após, será descrito o processo de mapeamento de competências de equipes desenvolvedoras interdisciplinares e dispostas nas considerações finais.

\section{COMPETÊNCIAS}

Esta pesquisa aborda as competências como sendo o conjunto de conhecimentos, habilidades e atitudes (CHA) necessários para resolução de funções, situações ou problemas, profissionais ou pessoais, com eficiência (BEHAR, 2013). Dessa forma, adota-se as definições abaixo.

- Conhecimento: relacionado ao saber conhecer. Refere-se à aprendizagem dos conhecimentos envolvidos e necessários ao desempenho de uma determinada função. Admite-se uma concepção construtivista, em que a construção do conhecimento encontra-se na interação entre o sujeito e o objeto, segundo a teoria de Piaget (1990).

- Habilidade: relacionada ao saber fazer. Refere-se aos conhecimentos processuais e procedimentais que se aplicam a uma determinada situação; à escolha correta das estratégias responsáveis pela resolução de situações-problema.

- Atitude: relacionada ao saber ser. Envolve o domínio social, afetivo, a emoção e a motivação. Aborda a intelectualidade, autonomia, responsabilidade, gestão de pessoas, trabalho em equipe e equilíbrio emocional.

Seguindo esse contexto, considera-se o mapeamento de competências como a identificação do conjunto de conhecimentos, habilidades e atitudes necessários para a realização de uma determinada função com eficiência e eficácia. Além disso, normalmente a rotina leva o indivíduo a proceder com certo automatismo, perdendo o hábito de refletir sobre o que faz, de que forma e se haveria uma maneira melhor de proceder. Nesse sentido, o mapeamento de competências também auxilia na identificação de perfis e funções, assim como na avaliação de processos.

Desse modo, esta pesquisa observa o mapeamento de competências como um instrumento de apoio à atividade da equipe interdisciplinar desenvolvedora de MEDs. Demonstra-se um possível meio de identificar, organizar e relacionar as distintas funções do grupo de trabalho. Além disso, essa prática também corrobora:

- o auxílio no processo de escolha de pessoal e na formação dos membros da equipe. Ainda que não seja possível a organização de uma equipe interdisciplinar, os elaboradores estarão cientes dos conhecimentos, habilidades e atitudes que necessitarão desenvolver para a elaboração de MEDs.

- a localização pontual do setor responsável por possíveis erros ou inconsistências no material. Isso facilita a identificação da etapa responsável, os fatores envolvidos e sua correção. 
Cabe ressaltar o valor transitório de conhecimentos, habilidades e atitudes mapeados, como destaca Fleury e Fleury (2001), reportando essa realidade ao caráter dinâmico das tecnologias organizacionais, que constantemente acaba gerando novas necessidades de qualificação. Já Rossato (2002) sugere que sejam avaliadas as competências existentes na empresa e as competências fundamentais para o funcionamento dos processos de negócios, como forma de gerenciar a complexidade do mapeamento. No entanto, o caráter complexo do mapeamento de competências não implica em um ponto desfavorável à sua prática. Apenas alerta que a eficácia e confiabilidade de sua posterior utilização dependerá da cautela e detalhamento aplicados no processo de sua elaboração.

\section{PROCESSO DE MAPEAMENTO DE COMPETENCIAS PARA A CONSTRUÇÃO DE MATERIAIS EDUCACIONAIS DIGITAIS BASEADOS NO DESIGN PEDAGÓGICO}

Com o intuito de identificar e setorizar os conhecimentos, habilidades e atitudes necessários à equipe técnica (programador), gráfica (designer) e pedagógica (conteudista/professor), realizou-se um mapeamento de competências necessárias a equipes interdisciplinares desenvolvedoras de MEDs. A partir dele foi possível organizar, por área, as atividades envolvidas no processo de elaboração dos referidos materiais, contemplando assim, a articulação entre as diferentes funções dos membros do grupo de trabalho. Destacase que essas competências são voltadas a equipes desenvolvedoras, não havendo a necessidade de que uma única pessoa desenvolva todos os elementos identificados. Por meio da interação entre os integrantes (professor, designer e programador), ocorrerá a troca de conhecimento e o natural intercâmbio entre os referidos elementos de competências, assim como a articulação entre as diferentes funções de cada profissional.

O processo de elaboração do mapeamento ocorreu, primeiramente, por meio de pesquisa bibliográfica, analisando-se os principais fatores técnicos, gráficos e pedagógicos envolvidos na elaboração de MEDs. Nesse procedimento, seguiu-se a concepção do Design Pedagógico (TORREZZAN, 2009), uma vez que ele aborda os principais parâmetros para a construção interdisciplinar de materiais educacionais digitais.

Com base nesses indícios foi possível identificar os conhecimentos, habilidades e atitudes envolvidos na função de construir materiais educacionais digitais, conforme o quadro 1 a seguir. 
QUADRO 1 - Competências para a construção de materiais educacionais digitais baseados no design pedagógico

\begin{tabular}{|c|c|c|c|}
\hline \multicolumn{4}{|c|}{ Competências para a construção de materiais educacionais digitais baseados no design pedagógico } \\
\hline COMPETENCIAS & $\begin{array}{l}\text { CONHECIMENT } \\
\text { OS } \\
\text { saber conhecer }\end{array}$ & $\begin{array}{l}\text { HABILIDADES } \\
\text { saber fazer }\end{array}$ & $\begin{array}{l}\text { ATITUDES } \\
\text { saber ser }\end{array}$ \\
\hline \multicolumn{4}{|l|}{ Competência Geral } \\
\hline $\begin{array}{l}\text { Competência de } \\
\text { Trabalho em } \\
\text { Equipe }\end{array}$ & - Ética & $\begin{array}{l}\text { - Gerir equipe } \\
\text { - Interagir com outras áreas } \\
\text { - Fornecer e receber feedbacks } \\
\text { - Adequar projeto às necessidades das } \\
\text { outras equipes } \\
\text { - Comprometer-se com resultados } \\
\text { - Ter iniciativa } \\
\text { - Encontrar-se aberto ao diálogo } \\
\text { - Saber negociar decisões }\end{array}$ & $\begin{array}{l}\text { - Comunicativo } \\
\text { - Observador } \\
\text { - Pesquisador } \\
\text { - Criativo } \\
\text { - Perseverante } \\
\text { - Gerenciador } \\
\text { - Administrador } \\
\text { - Negociador }\end{array}$ \\
\hline \multicolumn{4}{|l|}{$\begin{array}{c}\text { Competências } \\
\text { Técnicas } \\
\end{array}$} \\
\hline $\begin{array}{l}\text { Competência de } \\
\text { Navegação }\end{array}$ & $\begin{array}{l}\text { - Usabilidade } \\
\text { - Acessibilidade } \\
\text { - Estilos de } \\
\text { Navegação } \\
\text { - Mapa do site }\end{array}$ & $\begin{array}{l}\text { - Projetar } \\
\text { - Executar o projeto } \\
\text { - Avaliar }\end{array}$ & $\bullet$ Criativo \\
\hline $\begin{array}{l}\text { Competência de } \\
\text { Programação }\end{array}$ & $\begin{array}{l}\text {-Linguagem } \\
\text { de programação } \\
\text { informática }\end{array}$ & -Programar & $\begin{array}{l}\text { - Criativo } \\
\text { - Pesquisador } \\
\text { - Perseverante }\end{array}$ \\
\hline \multicolumn{4}{|l|}{$\begin{array}{l}\text { Competências } \\
\text { Gráficas }\end{array}$} \\
\hline $\begin{array}{l}\text { Competência de } \\
\text { Planejamento e } \\
\text { Desenvolvimento } \\
\text { do material digital }\end{array}$ & $\begin{array}{l}\text { - Metodologia de } \\
\text { projeto }\end{array}$ & $\begin{array}{l}\text { - Planejar e executar o processo de } \\
\text { construção do material digital } \\
\text { - Avaliar constantemente o processo e } \\
\text { readequa-lo sempre que necessário }\end{array}$ & $\begin{array}{l}\text { - Comunicativo } \\
\text { - Observador } \\
\text { - Gerenciador } \\
\text {-Administrador }\end{array}$ \\
\hline $\begin{array}{l}\text { Competência de } \\
\text { Identidade Visual }\end{array}$ & $\begin{array}{l}\text { - Composição } \\
\text { visual } \\
\text { - Carga Cognitiva } \\
\text { - Ergonomia } \\
\text { - Linguagem }\end{array}$ & $\begin{array}{l}\text { - Expressar-se visualmente } \\
\text { - realizar o planejamento gráfico do } \\
\text { material } \\
\text { - Preparar elementos gráficos } \\
\text { apropriados para a(s) mídia (s) abordada } \\
\text { (s) }\end{array}$ & $\begin{array}{l}\text { - Comunicativo } \\
\text { - Criativo }\end{array}$ \\
\hline $\begin{array}{c}\text { Competência do } \\
\text { Design Pedagógico }\end{array}$ & $\begin{array}{l}\text { - Semiótica } \\
\text { - Estética Digital } \\
\text { - Arte Interativa }\end{array}$ & $\begin{array}{l}\text { - Integrar diferentes mídias } \\
\text { - Possibilitar interação entre aluno, } \\
\text { professor e conteúdo por meio da } \\
\text { interatividade das interfaces gráficas }\end{array}$ & $\begin{array}{l}\text { - Criativo } \\
\text { - Comunicativo } \\
\text { - Observador }\end{array}$ \\
\hline \multicolumn{4}{|l|}{$\begin{array}{l}\text { Competências } \\
\text { Pedagógicas }\end{array}$} \\
\hline $\begin{array}{l}\text { Competência } \\
\text { Didática }\end{array}$ & $\begin{array}{l}\text { - Comunicação } \\
\text { didática } \\
\text { - Teorias do } \\
\text { conhecimento } \\
\text { - Planejamento } \\
\text { Pedagógico }\end{array}$ & $\begin{array}{l}\text { - Selecionar o conteúdo } \\
\text { - Planejar a abordagem do conteúdo } \\
\text { - Planejar situações de aprendizagem em } \\
\text { que o aluno possa atuar com uma postura } \\
\text { autônoma e investigativa } \\
\text { - Selecionar as mídias mais adequadas } \\
\text { para a abordagem do conteúdo }\end{array}$ & $\begin{array}{l}\text { - Criativo } \\
\text { - Pesquisador }\end{array}$ \\
\hline
\end{tabular}




\begin{tabular}{|c|c|c|c|}
\hline $\begin{array}{c}\text { Competência do } \\
\text { Design Pedagógico }\end{array}$ & $\begin{array}{l}\text { - Semiótica } \\
\text { - Experiência } \\
\text { estética } \\
\text { - Educação por } \\
\text { competências }\end{array}$ & $\begin{array}{l}\text { - Elaborar dinâmicas pedagógicas que } \\
\text { envolvam o desenvolvimento de } \\
\text { conhecimentos, habilidades e atitudes } \\
\text { - Abordar a experiência estética em } \\
\text { práticas pedagógicas }\end{array}$ & $\begin{array}{l}\text { - Criativo } \\
\text { - Comunicativo } \\
\text { - Pesquisador }\end{array}$ \\
\hline
\end{tabular}

Fonte: Torrezzan; Behar (2013, p.258)

No Quadro 1, esses elementos (conhecimentos, habilidades e atitudes) são organizados por competências. Estas, por sua vez, são distribuídas nos diferentes setores da equipe desenvolvedora (técnico, gráfico e pedagógico), com o objetivo de colaborar para a articulação entre as diferentes funções dos seus membros. Desse modo, é realizado o primeiro mapeamento das competências necessárias à construção de materiais educacionais digitais, a partir de pesquisa bibliográfica. A sua complementação e validação é disposta nas seções a seguir.

\section{Processo de validação das competências de equipes desenvolvedoras de materiais educacionais digitais}

O processo de validação do mapeamento das competências de equipes desenvolvedoras de MEDs foi realizado em três fases: Construção e Utilização do MED CompEMed; Cruzamento entre os mapeamentos realizados; e Aplicação de questionário, detalhadas a seguir.

\section{Fase A) Construção e Utilização do OA CompEMed em curso de extensão}

A partir do mapeamento de competências realizado, elaborou-se o objeto de aprendizagem CompEMed, sigla que corresponde à expressão competências das equipes desenvolvedoras de MEDs. O intuito foi utilizá-lo como apoio no processo de validação do referido mapeamento. O CompEMed é um artefato digital desenvolvido com o objetivo de gerar discussões a respeito dos fatores envolvidos na prática da equipe desenvolvedora de materiais educacionais digitais. Logo, esse material visa relacionar conceitos a respeito de MEDs: definição, metodologias de construção, design pedagógico (TORREZZAN, 2009) e a articulação entre as diferentes funções da equipe interdisciplinar pela gestão por competências. Nessa perspectiva, ao longo dos seus módulos de conteúdo, são abordados aspectos importantes na construção de MEDs, culminando em um conjunto de desafios que denotam um mapeamento de competências de equipes desenvolvedoras de materiais educacionais digitais. Encontra-se disponibilizado na web por meio do endereço eletrônico http://www.nuted.ufrgs.br/oa/CompEMed/, no intuito de compartilhar os conceitos abordados pelo presente estudo e colaborar com a formação de equipes desenvolvedoras de MEDs.

O objeto de aprendizagem CompEMed foi utilizado no curso de extensão denominado "Competências de Equipes Desenvolvedoras de Materiais Educacionais Digitais", destinado a professores e alunos das áreas de educação, programação e design envolvidos na elaboração de materiais educacionais digitais. Ocorreu nos meses de novembro e dezembro de 2013, na Universidade Federal do Rio Grande do Sul (UFRGS). 
Participaram 25 alunos, todos com alguma experiência na elaboração de MEDs. O intuito deles foi obter uma capacitação atualizada sobre o processo de construção desses materiais didáticos. Para este estudo o objetivo foi promover um segundo mapeamento de competências de equipes desenvolvedoras de MEDs, desta vez elaborado por equipes interdisciplinares atuantes. Totalizando $40 \mathrm{~h} / \mathrm{a}$, o curso abordou os principais fatores técnicos, gráficos e pedagógicos envolvidos na elaboração de MEDs, culminando na atividade de identificação das competências necessárias à prática de equipes desenvolvedoras interdisciplinares. Embora o curso tenha sido presencial, utilizou-se o ambiente virtual de aprendizagem (AVA) ROODA (Rede cooperativa de aprendizagem), possibilitando a utilização das funcionalidades: diário de bordo, Webfólio e Fórum de discussão. O intuito foi possibilitar práticas colaborativas e o registro de dados referentes às práticas realizadas e à trajetória de cada aluno.

A dinâmica aplicada em cada aula consistiu na abordagem de módulos do OA CompEMed, juntamente com a elaboração dos seus respectivos desafios. Dessa forma, aos poucos, discutiu-se sobre os principais fatores envolvidos na construção de materiais educacionais digitais. Após, em grupos, atividades relacionadas ao mapeamento de competências de equipes desenvolvedoras eram realizadas, de modo a tornar esse processo gradativo e o mais simples possível.

A turma foi organizada em três grupos: Pedagógico, Design e Programação (de acordo com a formação de cada aluno), justamente fazendo menção ao caráter interdisciplinar das equipes desenvolvedoras de MEDs. Optou-se por descrever, neste artigo, as atividades do curso relacionadas diretamente à elaboração do mapeamento de competências, embora conteúdos teóricos, análises e discussões também tenham sido abordadas e demonstraram-se importantes nesse processo. O procedimento utilizado foi baseado na metodologia de Leme (2012), por meio das atividades relacionadas a seguir.

Atividade 1) Realizada no Encontro 1: "Pensando nas pessoas com quem você convive na tarefa de desenvolvimento de MEDs, escreva uma lista dos comportamentos que você: gosta/não gosta/o ideal seria". A informalidade do exercício objetiva torná-lo o mais prático e intuitivo possível. Na realidade já se trata de uma pré-lista de atitudes. Cada grupo foi orientado a padronizar o quadro de forma a: escrever no infinitivo e de forma afirmativa; eliminar as frases duplicadas ou de mesmo sentido; e separar quando tivesse duas atitudes na mesma frase. 
QUADRO 2 - Lista padronizada referente à identificação de atitudes: Grupo Pedagógico

\begin{tabular}{|c|c|c|}
\hline Gosto & Não Gosto & O Ideal Seria \\
\hline $\begin{array}{l}\text { 1) Chega pontualmente. } \\
\text { Pontual } \\
\text { 2) Está sempre disposto a auxiliar e } \\
\text { sorrindo. } \\
\text { Prestativo } \\
\text { 3) Tem ideias originais. } \\
\text { Criativo } \\
\text { 4) É detalhista e cumpre os prazos. } \\
\text { Detalhista } \\
\text { Pontual } \\
\text { 5) É alegre-Não é uma atitude } \\
\text { 6) É competente noque faz.Não é } \\
\text { uma atitude }\end{array}$ & $\begin{array}{l}\text { 1) Quando faz comentários } \\
\text { maldosos a respeito de outros } \\
\text { colegas. } \\
\text { Ético } \\
\text { 2) Deixa para executar as ideias em } \\
\text { cima da hora. } \\
\text { Pontual } \\
\text { 3) Acumula muitas tarefas. } \\
\text { Organizado } \\
\text { 4) Não delega atividades para } \\
\text { realizarmos. } \\
\text { Gerenciador } \\
\text { 5) Sempre reclama de tudo. } \\
\text { Otimista }\end{array}$ & $\begin{array}{l}\text { 1) Fazer o comentário diretamente } \\
\text { com a pessoa relacionada ao } \\
\text { mesmo. } \\
\text { Ético } \\
\text { 2) Que se organize para executar as } \\
\text { ideias em um espaço de tempo } \\
\text { maior, evitando correria. } \\
\text { Organizado } \\
\text { 3) Delegar atividades, mas } \\
\text { deixando um espaço de tempo para } \\
\text { que a tarefa possa ser realizada } \\
\text { com êxito. } \\
\text { Gerenciador } \\
\text { Organizado } \\
\text { 4) Que pare de reclamar de tudo. } \\
\text { Entusiasmado }\end{array}$ \\
\hline
\end{tabular}

Fonte: Torrezzan (2014, p. 137 )

Atividade 2) Realizado no Encontro 2/tarde: "Vamos continuar a nossa reflexão sobre quais os elementos que a equipe desenvolvedora deve dominar ao elaborar um material educacional digital, iniciada no módulo 1? Então escreva uma lista de procedimentos técnicos que devem ser realizados pela equipe desenvolvedora durante a construção de MEDs. Para isso, baseie-se no que foi discutido neste módulo e na sua bagagem profissional sobre o assunto". Na realidade, estes "procedimentos técnicos" referem-se às habilidades envolvidas.

QUADRO 3 - Unificação dos procedimentos técnicos identificados pelos Grupos Pedagógico, Design e Programação

\begin{tabular}{|c|c|c|}
\hline Grupo Pedagógico & Grupo Design & Grupo Programação \\
\hline $\begin{array}{l}\text { - Elaborar o conteúdo } \\
\text { - Organizar a estrutura das páginas } \\
\text { - Desenvolver os procedimentos } \\
\text { - Explicitar os objetivos gerais e } \\
\text { específicos } \\
\text { - Estabelecer } \\
\text { estratégias/metodologias } \\
\text { aplicáveis ao público-alvo } \\
\text { - Desenvolver atividades/desafios } \\
\text { aplicáveis aos usuários } \\
\text { - Testar o objeto desenvolvido } \\
\text { antes de o mesmo ser } \\
\text { efetivamente aplicado } \\
\text { - Definir a avaliação do material } \\
\text { elaborado e do usuário }\end{array}$ & $\begin{array}{l}\text { - Público-alvo } \\
\text { - Perfil de acessibilidade do usuário } \\
\text { - Entendimento da proposta } \\
\text { pedagógica } \\
\text { - Conhecimento da plataforma de } \\
\text { suporte/programação/software } \\
\text { - Briefing com o professor } \\
\text { - Análises de referências } \\
\text { - Mapas mentais } \\
\text { - Detalhamento do projeto } \\
\text { Ícones } \\
\text { Cores } \\
\text { Fontes } \\
\text { Estrutura } \\
\text { - Esboço da proposta/pré-projeto } \\
\text { - Definição do fluxo de trabalho } \\
\text { - Cronograma } \\
\text { - Desenvolvimento } \\
\text { - Avaliação com a equipe } \\
\text { interdisciplinar } \\
\text { - Conclusão }\end{array}$ & $\begin{array}{l}\text { - Mapear (mapa conceitual) a } \\
\text { necessidade dos OAs } \\
\text { - Modelar os MEDs de acordo com } \\
\text { as necessidades do pedagogo e do } \\
\text { designer } \\
\text { - Escolher a linguagem e os } \\
\text { recursos mais apropriados e } \\
\text { verificar se os MEDs serão } \\
\text { multiplataforma e portáveis } \\
\text { - Desenvolver versão inicial do OA } \\
\text { - Testar e acompanhar piloto de } \\
\text { MEDs no público-alvo } \\
\text { - Finalizar a implementação } \\
\text { propriamente dita }\end{array}$ \\
\hline
\end{tabular}

Fonte: Torrezzan (2014, p. 138) 
Atividade 3) Realizado no Encontro 3: "A partir das listas realizadas anteriormente, foi possível identificar as atitudes e as habilidades necessárias ao desempenho de cada função da equipe desenvolvedora de MEDs. Agora, basta relacionar essas atitudes e habilidades a conhecimentos e, juntos, agrupá-los em competências - e estará realizado um mapeamento de competências de equipes desenvolvedoras de materiais educacionais digitais!" Nesta última atividade, os alunos concluíram o mapeamento de competências de equipes desenvolvedoras, sendo o resultado disposto a seguir:

QUADRO 4 - Mapeamento das competências de equipes desenvolvedoras de materiais educacionais digitais elaborado pelos alunos

\begin{tabular}{|c|c|c|c|}
\hline \multicolumn{4}{|c|}{ Resultado: Mapeamento de competências da equipe desenvolvedora de materiais educacionais digitais } \\
\hline COMPETÊNCIAS & $\begin{array}{c}\text { CONHECIMENTOS } \\
\text { Saber conhecer } \\
\end{array}$ & $\begin{array}{c}\text { HABILIDADES } \\
\text { Saber fazer }\end{array}$ & $\begin{array}{c}\text { ATITUDES } \\
\text { Saber ser } \\
\end{array}$ \\
\hline \multicolumn{4}{|c|}{ Competências Pedagógicas } \\
\hline $\begin{array}{l}\text { Competência de } \\
\text { Planejamento do } \\
\text { MED }\end{array}$ & $\begin{array}{l}\text { Funcionalidade de um } \\
\text { MED } \\
\text { Concepções pedagógicas } \\
\text { Conteúdos em foco } \\
\text { Contexto do usuário } \\
\text { Interdisciplinaridade } \\
\text { (temas transversais) }\end{array}$ & $\begin{array}{l}\text { Participar de reuniões } \\
\text { Trabalhar em equipe } \\
\text { Ter iniciativa } \\
\text { Compreender a diversidade de } \\
\text { ideias } \\
\text { Compartilhar certezas e dúvidas } \\
\text { Definir a fundamentação teórica } \\
\text { Planejar o material didático- } \\
\text { pedagógico com base no público- } \\
\text { alvo e nos conhecimentos, } \\
\text { habilidades e atitudes que } \\
\text { esperamos que os usuários } \\
\text { desenvolvam } \\
\text { Definir estrutura de avaliação } \\
\text { Explicitar os objetivos gerais e } \\
\text { específicos do material educacional } \\
\text { digital } \\
\text { Planejar diferentes desafios e } \\
\text { experiências estéticas aos usuários } \\
\text { nas atividades desenvolvidas no } \\
\text { MED }\end{array}$ & $\begin{array}{l}\text { Prestativo } \\
\text { Pontual } \\
\text { Cumpridor de } \\
\text { tarefas } \\
\text { Participativo } \\
\text { Presente } \\
\text { Objetivo } \\
\text { Responsável } \\
\text { Disponível } \\
\text { Organizado } \\
\text { Criativo } \\
\text { Profissional } \\
\text { Paciente } \\
\text { Humilde } \\
\text { Proativo } \\
\text { Flexível } \\
\text { Colaborativo } \\
\text { Pesquisador } \\
\text { Inovador } \\
\text { Compreensivo } \\
\text { Determinado } \\
\text { Democrático } \\
\text { Investigativo } \\
\text { Persistente }\end{array}$ \\
\hline $\begin{array}{c}\text { Competência de } \\
\text { Organização do } \\
\text { MED }\end{array}$ & $\begin{array}{l}\text { Aplicação das tecnologias } \\
\text { Funcionalidade de um } \\
\text { MED } \\
\text { Concepções pedagógicas } \\
\text { Conteúdos em foco } \\
\text { Contexto do usuário } \\
\text { Interdisciplinaridade } \\
\text { (temas transversais) }\end{array}$ & $\begin{array}{l}\text { Participar de reuniões } \\
\text { Trabalhar em equipe } \\
\text { Ter iniciativa } \\
\text { Buscar, conhecer e aplicar novas } \\
\text { tecnologias na educação } \\
\text { Criar alternativas para a construção } \\
\text { de aprendizagem por meio da } \\
\text { manipulação de diversos recursos } \\
\text { no objeto de aprendizagem } \\
\text { Especificar a interatividade entre o } \\
\text { objeto de aprendizagem e o usuário }\end{array}$ & $\begin{array}{l}\text { Prestativo } \\
\text { Pontual } \\
\text { Cumpridor de } \\
\text { tarefas } \\
\text { Participativo } \\
\text { Presente } \\
\text { Objetivo } \\
\text { Responsável } \\
\text { Disponível } \\
\text { Organizado } \\
\text { Criativo } \\
\text { Profissional } \\
\text { Competente } \\
\text { Paciente } \\
\text { Humilde } \\
\text { Proativo } \\
\text { Flexível } \\
\text { Colaborativo }\end{array}$ \\
\hline (C) ETD-Educ. Temal & Campinas, SP & p. 136-155 & \begin{tabular}{|l|l|}
6 & ISSN 1676-2592 \\
\end{tabular} \\
\hline
\end{tabular}




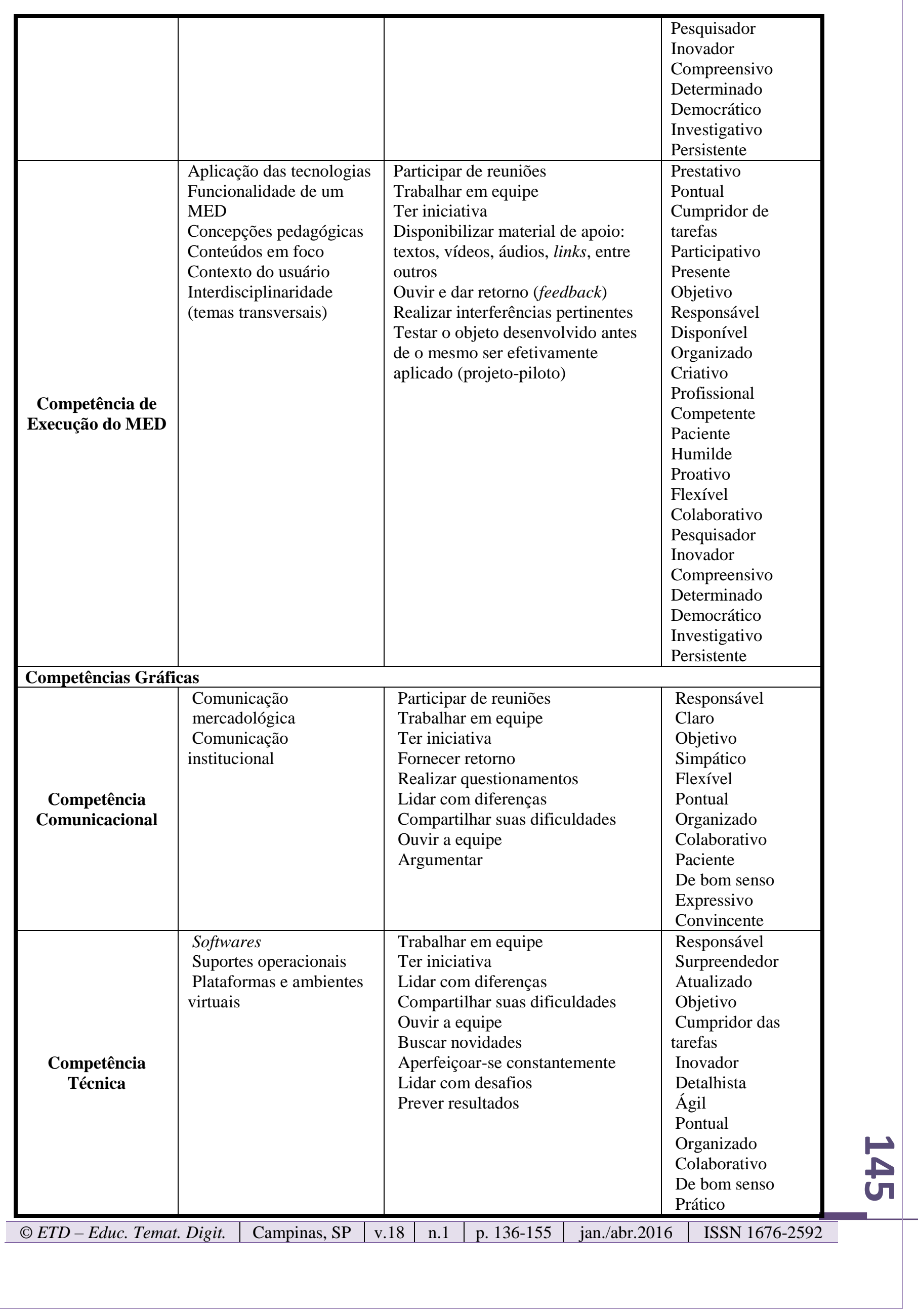




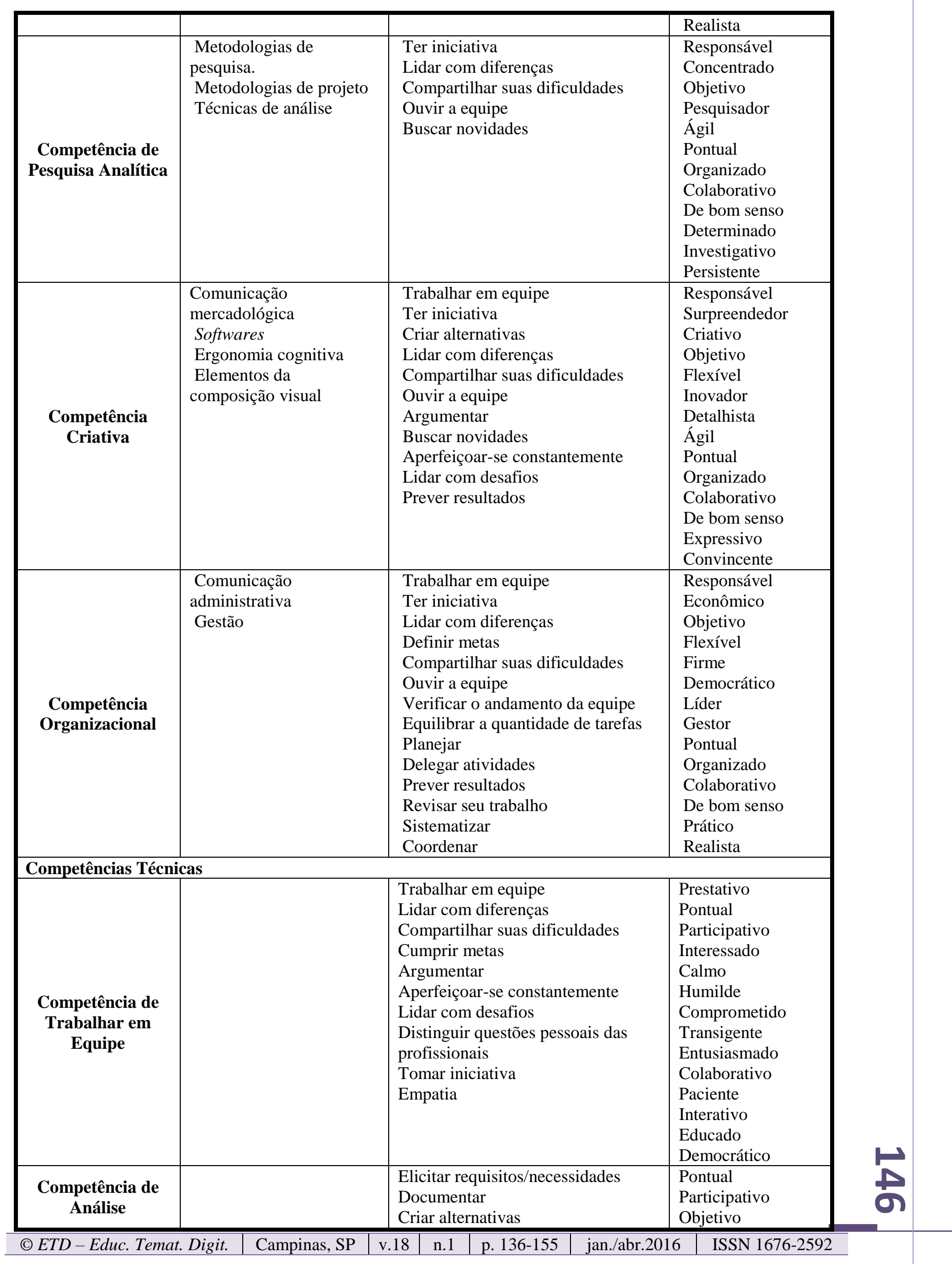




\begin{tabular}{|c|c|c|}
\hline & $\begin{array}{l}\text { Identificar requisitos } \\
\text { Definir, avaliar e adequar } \\
\text { casos/cenários } \\
\text { Pesquisar, selecionar e aplicar } \\
\text { tecnologias } \\
\text { Especificar/modelar o MED } \\
\text { Homologar o MED }\end{array}$ & $\begin{array}{l}\text { Responsável } \\
\text { Organizado } \\
\text { Criativo } \\
\text { Proativo } \\
\text { Comprometido } \\
\text { Atualizado } \\
\text { Seguro } \\
\text { Atento } \\
\text { Eficiente }\end{array}$ \\
\hline $\begin{array}{l}\text { Competência de } \\
\text { Desenvolvimento }\end{array}$ & $\begin{array}{l}\text { Documentar } \\
\text { Desenvolver protótipo } \\
\text { Desenvolver/implementar o MED } \\
\text { Aprimorar o MED }\end{array}$ & $\begin{array}{l}\text { Pontual } \\
\text { Objetivo } \\
\text { Responsável } \\
\text { Organizado } \\
\text { Criativo } \\
\text { Atualizado } \\
\text { Colaborativo } \\
\text { Seguro } \\
\text { Atento } \\
\text { Eficiente } \\
\text { Dinâmico } \\
\text { Prático } \\
\text { Realista }\end{array}$ \\
\hline $\begin{array}{c}\text { Competência de } \\
\text { Teste }\end{array}$ & $\begin{array}{l}\text { Definir, avaliar e adequar } \\
\text { casos/cenários } \\
\text { Verificar e validar o MED } \\
\text { Testar o MED }\end{array}$ & $\begin{array}{l}\text { Objetivo } \\
\text { Responsável } \\
\text { Organizado } \\
\text { Atento } \\
\text { Eficiente } \\
\text { Prático }\end{array}$ \\
\hline
\end{tabular}

Fonte: Torrezzan $(2014$, p.138)

Cada grupo, depois, forneceu o referido quadro de competências a coordenadores de equipes desenvolvedoras de MEDs (externos ao curso), responsáveis por acompanhar a programação, o planejamento pedagógico e o design de interface. Eles, por sua vez, avaliaram cada elemento de competência (referente à sua área de atuação) como "muito forte", "forte", "pouco necessário", "não se aplica". Aqueles considerados como "muito forte" e "forte" foram destacados, pois descrevem os elementos de competência essenciais à função. Leme (2012) utiliza a metáfora do copo d’água para melhor explicar essa questão. Segundo o autor, o copo representa uma determinada competência e a água refere-se aos seus elementos de competência (conhecimentos, habilidades e atitudes). O copo cheio significa $100 \%$ da competência, ou seja, $100 \%$ do CHA (conhecimentos, habilidades e atitudes). No entanto, Leme (2012) afirma que é possível determinar a quantidade mínima de água que deve haver no copo para que seja possível desempenhar determinada função com eficiência e eficácia - justamente os elementos classificados como "muito forte" e "forte". Em outras palavras, significa identificar o CHA essencial à função, quantificando o quanto daquela competência é necessário para realizar uma determinada tarefa.

A partir da classificação realizada pelos coordenadores, foi possível avaliar e quantificar matematicamente o quanto de cada competência é necessário às equipes desenvolvedoras para o desempenho da função de elaborar materiais educacionais digitais. Nesse sentido, primeiramente calculou-se o peso de cada indicador de competência (CHA): Peso indicador $=$ Nível máximo na escala/Quantidade de indicadores da competência. 
Para efetuar esse cálculo, foi preciso utilizar a Escala do Nível de Competências. Nesta pesquisa, adotou-se a escala recomendada por Leme (2012), dotada de cinco pontos com o objetivo de não haver alternativa central. Portanto, $100 \%$ de determinada competência equivale ao nível 5 da escala.

Após o cálculo do peso de cada indicador, calculou-se o nível de cada competência para a função por meio da fórmula:

NCF = (Nível máximo da escala/Quantidade de indicadores de competência) $\mathbf{x}$ (Quantidade de indicadores marcados como "muito forte" ou "forte" para a função). Resultado:

QUADRO 5 - Nível de cada competência para a função

\begin{tabular}{|c|c|c|c|c|c|}
\hline \multicolumn{6}{|c|}{$\begin{array}{l}\text { NÍVEL DE CADA COMPETÊNCIA PARA A FUNÇÃO } \\
\text { (Adaptada de Leme [2012]) }\end{array}$} \\
\hline COMPETÊNCIAS & $\begin{array}{l}\text { NÍVEL } \\
\text { MÁXIMO }\end{array}$ & $\begin{array}{l}\text { QUANTIDADE } \\
\text { DE } \\
\text { INDICADORES } \\
\text { (CHA) }\end{array}$ & $\begin{array}{l}\text { PESO DE } \\
\text { CADA } \\
\text { INDICADOR }\end{array}$ & $\begin{array}{l}\text { INDICADORES } \\
\text { MARCADOS } \\
\text { COMO "MUITO } \\
\text { FORTE" OU } \\
\text { "FORTE" }\end{array}$ & NCF \\
\hline \multicolumn{6}{|c|}{ Competências Pedagógicas } \\
\hline $\begin{array}{c}\text { Competência de } \\
\text { Planejamento do } \\
\text { MED }\end{array}$ & 5 & 38 & 0,131 & 9 & 1,2 \\
\hline $\begin{array}{c}\text { Competência de } \\
\text { Organização do } \\
\text { MED }\end{array}$ & 5 & 35 & 0,142 & 9 & 1,3 \\
\hline $\begin{array}{c}\text { Competência de } \\
\text { Execução do MED }\end{array}$ & 5 & 37 & 0,135 & 8 & 1,1 \\
\hline \multicolumn{6}{|c|}{ Competências Gráficas } \\
\hline $\begin{array}{l}\text { Competência } \\
\text { Comunicacional }\end{array}$ & 5 & 23 & 0,217 & 4 & 0,9 \\
\hline $\begin{array}{l}\text { Competência } \\
\text { Técnica }\end{array}$ & 5 & 26 & 0,192 & 11 & 2,1 \\
\hline $\begin{array}{c}\text { Competência de } \\
\text { Pesquisa Analítica }\end{array}$ & 5 & 20 & 0,25 & 10 & 2,5 \\
\hline $\begin{array}{c}\text { Competência } \\
\text { Criativa }\end{array}$ & 5 & 29 & 0,172 & 10 & 1,72 \\
\hline $\begin{array}{c}\text { Competência } \\
\text { Organizacional }\end{array}$ & 5 & 30 & 0,166 & 12 & 2,0 \\
\hline \multicolumn{6}{|c|}{ Competências Técnicas } \\
\hline $\begin{array}{c}\text { Competência de } \\
\text { Trabalhar em } \\
\text { Equipe }\end{array}$ & 5 & 24 & 0,208 & 9 & 1,9 \\
\hline $\begin{array}{c}\text { Competência de } \\
\text { Análise }\end{array}$ & 5 & 20 & 0,25 & 10 & 2,5 \\
\hline $\begin{array}{c}\text { Competência de } \\
\text { Desenvolvimento }\end{array}$ & 5 & 17 & 0,294 & 8 & 2,4 \\
\hline $\begin{array}{c}\text { Competência de } \\
\text { Teste }\end{array}$ & 5 & 9 & 0,55 & 7 & 3,9 \\
\hline
\end{tabular}

Fonte: Torrezzan (2014, p. 147) 
Em uma análise quantitativa do NCF, foi possível verificar o quanto cada competência é importante para a função de elaborar materiais educacionais digitais (o quanto de água tem em cada copo). Já do ponto de vista qualitativo, a avaliação dos coordenadores possibilitou visualizar quais são os principais indicadores de cada competência, ou seja, do que aquela água que está em cada copo é composta (CHA classificados como "muito forte" e "forte").

O objetivo principal desse segundo mapeamento, realizado no curso de extensão, foi obter um mapeamento de competências de equipes desenvolvedoras de materiais educacionais digitais realizado por profissionais externos a esta pesquisa. Dessa forma, embora o conteúdo trabalhado no curso traga consigo o viés deste estudo, tornou-se possível incorporar a ele elementos externos, referentes à prática de equipes interdisciplinares. Assim, esses resultados obtidos foram posteriormente cruzados com o primeiro mapeamento realizado, conforme exposto na seção a seguir.

Fase B) Cruzamento entre o primeiro mapeamento, realizado com base no referencial desta pesquisa, e o segundo, efetuado em curso de extensão

Nesta etapa da pesquisa, realizou-se o cruzamento entre os dois mapeamentos elaborados, originando as competências necessárias à construção de materiais educacionais digitais baseados no design pedagógico. Como se optou por não interferir na realização do mapeamento efetuado no curso de extensão, utilizou-se este momento para avaliar as competências e o CHA identificados pelos alunos. Eliminaram-se alguns itens que, na realidade, não são considerados elementos de competência, como, por exemplo: "ser verdadeiro", "ser calmo", "ser educado", pois se trata de juízos de valor ou "boa conduta". De forma geral, observou-se uma grande semelhança entre os dados dos dois mapeamentos. Foi revista a listagem de conhecimentos, habilidades e atitudes por competência, assim como incorporados novos elementos (CHA). O resultado é disposto no quadro a seguir.

QUADRO 6 - Competências para a construção de materiais educacionais digitais baseados no design pedagógico

\begin{tabular}{|c|c|c|c|}
\hline \multicolumn{4}{|c|}{ Competências para a construção de materiais educacionais digitais baseados no design pedagógico } \\
\hline COMPETÊNCIAS & $\begin{array}{l}\text { CONHECIMENTOS } \\
\text { saber conhecer }\end{array}$ & $\begin{array}{c}\text { HABILIDADES } \\
\text { saber fazer }\end{array}$ & $\begin{array}{r}\text { ATITUDES } \\
\text { saber ser }\end{array}$ \\
\hline \multicolumn{4}{|l|}{ Competência Geral } \\
\hline $\begin{array}{c}\text { Competência de } \\
\text { Trabalho em Equipe }\end{array}$ & - Ética & $\begin{array}{l}\text { - Gerir equipe } \\
\text { - Interagir com outras áreas } \\
\text { - Fornecer e receber feedbacks } \\
\text { - Adequar o projeto às necessidades } \\
\text { das outras equipes } \\
\text { - Comprometer-se com resultados } \\
\text { - Ter iniciativa } \\
\text { - Encontrar-se aberto ao diálogo } \\
\text { - Saber negociar decisões } \\
\text { - Avaliar resultados }\end{array}$ & $\begin{array}{l}\text { - Comunicativo } \\
\text { - Observador } \\
\text { - Pesquisador } \\
\text { - Criativo } \\
\text { - Perseverante } \\
\text { - Gerenciador } \\
\text { - Administrador } \\
\text { - Negociador } \\
\text { - Organizado } \\
\text { - Colaborativo } \\
\text { - Flexível }\end{array}$ \\
\hline $\begin{array}{c}\text { Competência de } \\
\text { Pesquisa }\end{array}$ & $\begin{array}{l}\text { - Metodologia de } \\
\text { pesquisa }\end{array}$ & $\begin{array}{l}\text { - Pesquisar elementos e materiais } \\
\text { análogos que poderão auxiliar o } \\
\text { planejamento e a execução do MED } \\
\text { - Ter iniciativa } \\
\text { - Elicitar requisitos/necessidades }\end{array}$ & $\begin{array}{l}\text { - Observador } \\
\text { - Investigativo } \\
\text { - Criativo }\end{array}$ \\
\hline (C) ETD-Educ. Temat. D & Campinas, SP & jan./abr.2016 & ISSN 1676-2592 \\
\hline
\end{tabular}




\begin{tabular}{|c|c|c|c|}
\hline $\begin{array}{c}\text { Competência do } \\
\text { Design Pedagógico }\end{array}$ & $\begin{array}{l}\text { Todas as equipes } \\
\text { - Design pedagógico } \\
\text { Equipe Pedagógica } \\
\text { - Educação por } \\
\text { competências } \\
\text { - Experiência estética } \\
\text { Equipe Gráfica } \\
\text { - Interatividade } \\
\text { homem-máquina } \\
\text { - Estética digital } \\
\text { - Arte interativa } \\
\text { - Experiência estética } \\
\text { Equipe Técnica } \\
\text { - Interatividade } \\
\text { homem-máquina } \\
\text { - Experiência estética }\end{array}$ & $\begin{array}{l}\text { Equipe Pedagógica } \\
\text { - Abordar o conteúdo na forma de } \\
\text { práticas educacionais que } \\
\text { possibilitem ao aluno a investigação } \\
\text { do objeto de estudo por meio da } \\
\text { elaboração de estratégias de ação e } \\
\text { testagem de hipóteses } \\
\text { - Planejar dinâmicas pedagógicas } \\
\text { que possibilitem ao aluno o } \\
\text { desenvolvimento de conhecimentos, } \\
\text { habilidades e atitudes } \\
\text { - Abordar a experiência estética em } \\
\text { práticas educacionais } \\
\text { Equipe Gráfica } \\
\text { - Integrar diferentes mídias } \\
\text { - Possibilitar interação entre aluno, } \\
\text { professor e conteúdo por meio da } \\
\text { interatividade das interfaces gráficas } \\
\text { Equipe Técnica } \\
\text { - Programar o sistema de modo a } \\
\text { disponibilizar uma interatividade } \\
\text { usuário-MED baseada em feedbacks } \\
\text { que apoiem a ação crítica e a } \\
\text { testagem de hipóteses por parte do } \\
\text { aluno }\end{array}$ & $\begin{array}{l}\text { - Criativo } \\
\text { - Comunicativo } \\
\text { - Pesquisador }\end{array}$ \\
\hline \multicolumn{4}{|l|}{ Competências Técnicas } \\
\hline $\begin{array}{l}\text { Competência de } \\
\text { Navegação }\end{array}$ & $\begin{array}{l}\text { - Usabilidade } \\
\text { - Acessibilidade } \\
\text { - Estilos de navegação } \\
\text { - Mapa do site }\end{array}$ & $\begin{array}{l}\text { - Executar o projeto do MED } \\
\text { - Avaliar o protótipo }\end{array}$ & - Criativo \\
\hline $\begin{array}{l}\text { Competência de } \\
\text { Programação }\end{array}$ & $\begin{array}{l}\text { - Linguagem } \\
\text { de programação } \\
\text { informática }\end{array}$ & - Programar & $\begin{array}{l}\text { - Criativo } \\
\text { - Pesquisador } \\
\text { - Perseverante } \\
\text { - Objetivo }\end{array}$ \\
\hline \multicolumn{4}{|l|}{ Competências Gráficas } \\
\hline $\begin{array}{c}\text { Competência de } \\
\text { Planejamento e } \\
\text { Desenvolvimento do } \\
\text { Material Digital }\end{array}$ & $\begin{array}{l}\text { - Metodologia de } \\
\text { projeto } \\
\text { - Softwares de edição } \\
\text { gráfica }\end{array}$ & $\begin{array}{l}\text { - Planejar e executar o processo de } \\
\text { construção do material digital } \\
\text { - Avaliar constantemente o processo } \\
\text { e readequá-lo sempre que necessário }\end{array}$ & $\begin{array}{l}\text { - Comunicativo } \\
\text { - Observador } \\
\text { - Gerenciador } \\
\text { - Administrador }\end{array}$ \\
\hline $\begin{array}{l}\text { Competência de } \\
\text { Identidade Visual }\end{array}$ & $\begin{array}{l}\text { - Composição visual } \\
\text { - Carga cognitiva } \\
\text { - Ergonomia } \\
\text { - Comunicação visual }\end{array}$ & $\begin{array}{l}\text { - Integrar o planejamento visual ao } \\
\text { objetivo pedagógico do MED } \\
\text { - Realizar o planejamento gráfico do } \\
\text { material } \\
\text { - Preparar elementos gráficos } \\
\text { apropriados à(s) mídia(s) abordada(s) }\end{array}$ & $\begin{array}{l}\text { - Comunicativo } \\
\text { - Criativo }\end{array}$ \\
\hline \multicolumn{4}{|c|}{ Competências Pedagógicas } \\
\hline Competência Didática & $\begin{array}{l}\text { - Comunicação } \\
\text { didática } \\
\text { - Teorias do } \\
\text { conhecimento } \\
\text { - Planejamento } \\
\text { pedagógico }\end{array}$ & $\begin{array}{l}\text { - Selecionar o conteúdo } \\
\text { - Planejar a abordagem pedagógica } \\
\text { do conteúdo } \\
\text { - Planejar situações de aprendizagem } \\
\text { em que o aluno possa atuar com uma } \\
\text { postura autônoma e investigativa } \\
\text { - Selecionar as mídias mais } \\
\text { adequadas à abordagem do conteúdo } \\
\text { - Definir estrutura de avaliação } \\
\text { - Avaliar constantemente o processo } \\
\text { e readequá-lo sempre que necessário }\end{array}$ & $\begin{array}{l}\text { - Criativo } \\
\text { - Pesquisador } \\
\text { - Objetivo }\end{array}$ \\
\hline
\end{tabular}

Fonte: Torrezzan (2014, p.148) 
A partir dessa análise entre os dois mapeamentos avaliou-se o CHA inicialmente identificado por este estudo e agregou-se a ele novos elementos, baseados na experiência de equipes desenvolvedoras atuantes no desenvolvimento de materiais educacionais digitais. Também se observou a existência de alguns itens em comum ao planejamento pedagógico, técnico e gráfico, de modo a originar a "competência geral", adicionada ao mapeamento resultante. $\mathrm{Na}$ sequência, questionários foram utilizados para avaliar os elementos de competência decorrentes, sendo essa prática abordada na seção a seguir.

Fase C) Aplicação de questionário - classificação dos elementos de competência em "muito forte", "forte", "normal" e "não se aplica".

Tendo-se como referência a prática aplicada no curso de extensão realizado, elaborouse um questionário, na forma de planilhas, a ser preenchido por professores (conteudistas), pedagogos, programadores e designers atuantes em equipes desenvolvedoras de MEDs. O intuito foi identificar os elementos de competência (CHA) considerados como "muito forte" e "forte", segundo a metodologia de Leme (2012) e determinar o quanto de cada competência é indispensável para a função de construir MEDs.

Para a elaboração das planilhas, utilizou-se como referência a metodologia de Leme (2012), no entanto, houve a necessidade de adaptá-la ao viés desta pesquisa. Embora o referido autor considere que cada competência seja composta por conhecimentos, habilidades e atitudes, ele não aborda a distinção entre esses elementos, por considerar que traria certo grau de complexidade ao mapeamento. Por isso, em seu processo, dispõe o CHA em dois grupos gerais: as Competências Técnicas (conhecimentos e habilidades) e as Competências Comportamentais (atitudes). Por esse motivo, as planilhas apresentadas pelo autor em sua metodologia, destinadas à classificação das categorias "muito forte", "forte", "normal" e "não se aplica", tiveram que ser adaptadas a este estudo, de modo a tornar possível a distinção do CHA em cada competência. Dessa forma, optou-se por utilizar duas planilhas para cada profissional, de modo a evitar que ficassem maçantes, com muitos elementos para analisar. A primeira conteve as atitudes, e a segunda abrangeu os conhecimentos e as habilidades. Salienta-se que nenhum participante inseriu novas competências ou novos elementos (CHA) nas planilhas, embora tenha sido disponibilizado espaço para essa finalidade.

Foram analisadas as planilhas de 13 designers, 8 pedagogos e 11 programadores, recebidas entre julho e setembro de 2014, abrangendo distintas equipes desenvolvedoras de materiais educacionais digitais, entre elas: a Fábrica de Objetos de Aprendizagem da Unisinos e o Núcleo de Apoio Pedagógico à Educação a Distância (NAPEAD/UFRGS), referências nesta área.

A partir da análise desses dados coletados, verificou-se que praticamente todos os conhecimentos, habilidades e atitudes foram considerados, por unanimidade, como "muito forte" ou "forte", com exceção dos elementos expostos no quadro 7 : 
QUADRO 7- Elementos de competência não marcados como "forte" ou "muito forte"

\begin{tabular}{|c|c|c|}
\hline \multirow{3}{*}{ Pedagogo/Conteudista } & Habilidades & Atitudes \\
\cline { 2 - 3 } & & Perseverante \\
& Gerir equipe & Gerenciador \\
& & Administrador \\
& & Negociador \\
\hline Programador & ---------------- & Gerenciador \\
& & Administrador \\
\hline
\end{tabular}

Fonte: Torrezzan (2014, p. 157)

Em razão de as atitudes "gerenciador" e "administrador" (quadro 7) não terem sido, pela maioria dos participantes, classificadas como "muito forte" ou "forte" na planilha de dois profissionais (pedagogo e programador), elas foram excluídas do cálculo dos indicadores marcados como "muito forte" ou "forte" (apresentado a seguir). Já a habilidade e demais atitudes (quadro 7), como se referem à competência geral, denominada "competência de trabalho em equipe", e a maioria dos profissionais designers e programadores as considerou como "muito forte" e "forte", elas não serão excluídas do referido cálculo.

Como resultado final da análise desses dados coletados, tem-se o quadro a seguir:

QUADRO 8 - Nível de cada competência para a função

\begin{tabular}{|c|c|c|c|c|c|}
\hline \multicolumn{6}{|c|}{$\begin{array}{c}\text { NÍVEL DE CADA COMPETÊNCIA PARA A FUNÇÃO } \\
\text { Adaptada de Leme (2012) }\end{array}$} \\
\hline COMPETÊNCIAS & $\begin{array}{l}\text { NÍVEL } \\
\text { MÁXIMO }\end{array}$ & $\begin{array}{c}\text { QUANTIDADE } \\
\text { DE } \\
\text { INDICADORES } \\
\text { (CHA) }\end{array}$ & $\begin{array}{c}\text { PESO DE } \\
\text { CADA } \\
\text { INDICADOR }\end{array}$ & $\begin{array}{l}\text { INDICADORES } \\
\text { MARCADOS } \\
\text { COMO "MUITO } \\
\text { FORTE" OU } \\
\text { "FORTE" }\end{array}$ & NCF \\
\hline \multicolumn{6}{|l|}{ Competência Geral } \\
\hline $\begin{array}{l}\text { Competência de } \\
\text { Trabalho em Equipe }\end{array}$ & 5 & 21 & 0,238 & 21 & 5 \\
\hline $\begin{array}{l}\text { Competência de } \\
\text { Pesquisa }\end{array}$ & 5 & 7 & 0,714 & 7 & 5 \\
\hline $\begin{array}{l}\text { Competência do Design } \\
\text { Pedagógico }\end{array}$ & 5 & 15 & 0,333 & 15 & 5 \\
\hline \multicolumn{6}{|l|}{$\begin{array}{c}\text { Competências } \\
\text { Técnicas }\end{array}$} \\
\hline $\begin{array}{l}\text { Competência de } \\
\text { Navegação }\end{array}$ & 5 & 7 & 0,714 & 7 & 5 \\
\hline $\begin{array}{l}\text { Competência de } \\
\text { Programação }\end{array}$ & 5 & 6 & 0,830 & 6 & 5 \\
\hline \multicolumn{6}{|l|}{$\begin{array}{l}\text { Competências } \\
\text { Gráficas }\end{array}$} \\
\hline $\begin{array}{c}\text { Competência de } \\
\text { Planejamento e } \\
\text { Desenvolvimento do } \\
\text { Material Digital } \\
\end{array}$ & 5 & 8 & 0,625 & 8 & 5 \\
\hline $\begin{array}{l}\text { Competência de } \\
\text { Identidade Visual }\end{array}$ & 5 & 9 & 0,555 & 9 & 5 \\
\hline \multicolumn{6}{|l|}{$\begin{array}{c}\text { Competências } \\
\text { Pedagógicas }\end{array}$} \\
\hline Competência Didática & 5 & 12 & 0,416 & 12 & 5 \\
\hline
\end{tabular}

Fonte: Torrezzan (2014, p. 157) 
A partir da análise do resultado dos dados coletados, é possível interpretar que o mapeamento resultante aborda as competências essenciais à função de desenvolver materiais educacionais digitais baseados no design pedagógico, todas no mesmo grau de importância e com $100 \%$ do seu CHA. Esse dado revela que o mapeamento de competências originado é focado e objetivo, identificando os conhecimentos, as habilidades $\mathrm{e}$ as atitudes imprescindíveis para a função de desenvolver MEDs. Outro princípio que aponta essa conclusão é o fato de nenhum colaborador ter sugerido a inserção de algum CHA ou competência às planilhas da coleta de dados. Além disso, a obtenção do mesmo nível para a função (NCF) expressa o equilíbrio entre as competências gráficas, técnicas e pedagógicas e, portanto, a necessidade do trabalho interdisciplinar. Por sua vez, essa prática, a partir deste estudo, encontrar-se-á apoiada pelo mapeamento de competências resultante, pois, uma vez conhecidas as responsabilidades de cada profissional envolvido, será possível elaborar um percurso metodológico focado, interativo e colaborativo.

Portanto, a partir deste mapeamento, e posterior processo de validação, foi possível identificar as competências necessárias às equipes desenvolvedoras para a construção de materiais educacionais digitais baseados no design pedagógico. Ele propicia a setorização das atividades envolvidas no processo de elaboração dos referidos materiais, de modo a colaborar com a articulação entre as diferentes funções do grupo de trabalho. Além disso, auxilia na escolha dos membros da equipe, já que delineia o perfil de cada profissional; assim como na identificação dos elementos que poderão auxiliar a corrigir inconsistências que venham a surgir durante o processo construtivo de MEDs.

Logo, pretende-se, por meio deste mapeamento, apoiar a prática de equipes desenvolvedoras e sugerir uma reflexão sobre o processo interdisciplinar de construção de materiais educacionais digitais, uma vez baseado nas competências da equipe.

\section{CONSIDERAÇÕES FINAIS}

A construção de materiais educacionais digitais envolve a integração de fatores técnicos, gráficos e pedagógicos, implicando um grau de complexidade à atividade da equipe desenvolvedora. O planejamento pedagógico necessita ser apoiado pelo design gráfico das interfaces e pela programação informática a ser implementada. Desse modo, este estudo identificou as competências necessárias às equipes desenvolvedoras interdisciplinares para o desenvolvimento de materiais educacionais digitais. O intuito é, a partir da divulgação dos resultados obtidos, auxiliar a gestão e a integração entre as diferentes funções de cada profissional envolvido nesta prática.

No desenvolvimento deste trabalho, primeiramente investigou-se os principais fatores envolvidos na elaboração de MEDs, por meio da organização de referencial teórico. Após, esses elementos foram desdobrados em conhecimentos, habilidades e atitudes, denotando as competências necessárias à construção de materiais educacionais digitais baseados no design pedagógico. Na sequência, efetuou-se o processo de validação do referido mapeamento por meio da utilização do OA CompEMed em curso de extensão. Nele, os alunos - profissionais 
envolvidos na construção de MEDs -, a partir da realização das atividades do OA CompEMed, organizaram um segundo mapeamento de competências de equipes desenvolvedoras de materiais educacionais digitais. Esse mapeamento foi cruzado com o primeiro (efetuado com base em referencial teórico). O resultado dessa integração foi avaliado, por meio de um questionário, por outros profissionais (pedagogos, designers e programadores) com experiência na elaboração de MEDs. A partir deles foi possível validar o mapeamento de competências de equipes desenvolvedoras de materiais educacionais digitais baseados no design pedagógico. Por sua vez, os conhecimentos, habilidades e atitudes identificados poderão colaborar com a formação continuada dos profissionais envolvidos na construção de MEDs; assim como orientar a escolha do grupo de trabalho e a interlocução entre as funções dos seus distintos membros. O objetivo é apoiar a prática de equipes desenvolvedoras de MEDs e atentar para a importância do processo interdisciplinar de construção de MEDs baseado nas competências da equipe.

\section{REFERÊNCIAS}

BEHAR, Patricia Alejandra (Org.). Competências em educação a distância. Porto Alegre: Penso, 2013, $312 \mathrm{p}$.

DAVENPORT, Thomas; PRUSAK, Laurence. Conhecimento empresarial: como as organizações gerenciam o capital intelectual. 18. ed. Rio de Janeiro: Campus, 1998, 256 p.

FLEURY, Maria Tereza Leme; FLEURY, Afonso. Construindo o conceito de competências. Revista de Administração Contemporânea, Curitiba, PR, v. 5. 2001. Disponível em: <http://goo.gl/6vvj> Acesso em: 10 mar. 2016. ISSN 1982-7849.

LEME, Rogério. Aplicação prática de gestão de pessoas por competências - mapeamento, treinamento, seleção, avaliação e mensuração de resultados de treinamento. Rio de Janeiro: Qualitymark, 2012, 244 p.

PIAGET, Jean. Epistemologia genética. 3. ed. São Paulo: Martins Fontes, 1990, 124 p.

ROSSATO, Maria Antonieta. Uma proposta de modelo de gestão do conhecimento. 2002. Tese (Doutorado em Ciências em Engenharia de Produção) - Faculdade de Engenharia, Universidade Federal do Rio de Janeiro, Rio de Janeiro, RJ, 2002.

TORREZZAN, Cristina Alba Wildt, et al. Objeto de aprendizagem CompEMed. 2012. Disponível em: < http://goo.gl/IERyqg>. Acesso em 10 mar. 2016.

TORREZZAN, Cristina Alba Wildt; BEHAR, Patricia Alejandra. Competências para a construção de materiais educacionais digitais baseados no design pedagógico. In: BEHAR, Patricia Alejandra (Org.). Competências em educação a distância. Porto Alegre: Penso, 2013, 312 p. 
TORREZZAN, Cristina Alba Wildt. Design pedagógico: um olhar na construção de materiais educacionais digitais. 2009. 208 f. Dissertação (Mestrado em Educação) Faculdade de Educação, Universidade Federal do Rio Grande do Sul, Porto Alegre, RS, 2009. Disponível em: 〈https://goo.gl/SWlSmZ>. Acesso em: 05 jul. 2015.

TORREZZAN, Cristina Alba Wildt. ConstruMed: Metodologia para a construção de materiais educacionais digitais baseados no design pedagógico. 2014. 240 f. Tese (Doutorado em Informática na Educação) - Centro de Estudos Interdisciplinares em Novas Tecnologias na Educação, Universidade Federal do Rio Grande do Sul, Porto Alegre, RS, 2014. Disponível em: < http://goo.gl/lq8B1g>. Acesso em: 05 jul. 2015.

Como citar este documento:

TORREZZAN, Cristina Alba Wildt; BEHAR, Patrícia Alejandra, Mapeamento de competências de equipes desenvolvedoras: um olhar na construção interdisciplinar de materiais educacionais digitais. ETD - Educação Temática Digital, Campinas, SP, v. 18, n. 1, p. 136-155, abr. 2016. ISSN 1676-2592. Disponível em: <http://periodicos.sbu.unicamp.br/ojs/index.php/etd/article/view/8638211>. Acesso em: 05 abr. 2016. doi: 〈http://dx.doi.org/10.20396/etd.v18i1.8638211>. 